\title{
Context, Expectation and Conversational Implicature: A Pragmatic Analysis of Good
}

\author{
Jiyon Cook \\ Department of British and American Literature and Culture, Sogang University, Seoul, South Korea
}

\begin{abstract}
From a neo-Gricean perspective, Q-inference-based accounts of the interpretation of scalar expressions have been elaborated. This paper analyses the communicated meanings of English good, an example of a common scalar expression, by focusing on the loose or casual use of language in daily English in a neutral context. It shows that the use of good, which is understood to induce scalar implicature, can frequently result in I-inference. While Q-inference is based on linguistic factors (specifically, the semantic strength of linguistic expressions), I-inference is guided by ideas in common. This paper stresses that deriving a scalar implicature from good depends on the degree to which the listener is sensitive to type of context and to expectation.
\end{abstract}

Index Terms—good, Q-inference, scalar implicature, I-inference, I-implicature, context, expectation, First Maxim of Quantity, Second Maxim of Quantity

\section{INTRODUCTION}

This paper tries to explicate the semantic underspecification of the English scalar expression good by looking at the meaning of good in the three types of context suggested by Katsos, Breheny, and Williams (2005), namely, upwardentailing structures with upper-bound, lower-bound, and neutral discourse contexts. The recovery of the communicated meanings of good in a neutral context and the inferential aspects of this recovery are discussed in detail. We will address the gap between good's well-known default conversational implicature (scalar implicature) and the meanings speakers express by it in loose use.

The analytic framework of this study refers to Levinson's (2000) pragmatic principles, specifically the Q-principle and the I-principle. According to the Q-principle, the speaker provides sufficient information (and not less), and thus the listener tends to interpret what is unsaid as untrue. According to the I-principle, the speaker provides the necessary amount of information (and not more), and thus, the listener tends to interpret what left unsaid based on his or her own world knowledge. Observe example (1):

(1) Tom: It's OK. Oh. No, it's good.

Lisa: I know what you mean. It's not too excellent. It's not too bad. It's ... just good.

We can judge (1) to be plausible because we perceive good to be a scalar expression and the speaker to have some degree of quality in mind. Thus, (1) suggests that there is often a difference between the denotative meaning of good itself and the speaker's implicature in using it, and that the listener can infer the intended meaning. At first, it seems plausible to analyse the generalized conversational implicature of good as a scalar one. However, strictly speaking, the interpretative aspects of Lisa's interpretation of good (namely, It's not too bad, It's ... just good) are not derived from the Q[uantity]-inference (Inference under the influence of the Q-principle is called 'Q-inference'), and fall outside the realm of scalar implicature. Consider the following utterances:

(2) a. Teachers tell their students good things.

b. Good movies are popular.

In these utterances, the question of scalar implicature (<not excellent $>)$ as such does not arise. In (2a), good means literally and simply <good>. However, it can still carry some extra meaning, for instance, <helpful>. In (2b), good does not carry a scalar implicature; rather, it is interpreted in the sense of <well made>. That is, although good here is a scalar expression, it is not seen as automatically implicating the upper-binding meaning <not excellent> that the Qprinciple would induce. Here, in dealing with various uses of good, we raise the question of whether it is sufficient to take Levinson's view that the default meaning of good is <not excellent>. This paper shows that good in a neutral context also induces I-inference, and thus that some of the interpretations of good can be accounted for by applying Levinson's I-principle in addition to the Q-principle.

\section{LEVINSON'S ACCOUNT}

In general, it is supposed that we infer a Quantity-based implicature (scalar implicature) from a scalar predicate. For example, Horn (1989) and Levinson (2000) provide Q-inference-based accounts of the meanings of scalar expressions, in which the listener is capable of inferring the content of a scalar expression based on the assumption that the speaker is trying to provide information that is as sufficient as possible. 
The pragmatic meaning of good in English has been analysed by means of a scalar implicature derived by applying the Q[uantity]-principle from the perspective of neo-Gricean pragmatics (cf. Horn, 1989; Levinson, 2000). The Qprinciple, which is developed from Grice's First Maxim of Quantity ('Make your contribution as informative as is required') (Grice, 1975), focuses on the speaker's attempt to give sufficient verbal information to the listener as best she can. More precisely, it is as follows:

The Q-Principle (Levinson, 2000, p. 76)

'Do not provide a statement that is informationally weaker than your knowledge of the world allows, unless providing an informationally stronger statement would contravene the I-principle'.

In contrast, the I[nformativeness]-principle (Levinson, 2000) is developed from Grice's Second Maxim of Quantity ('Do not make your contribution more informative than is required') (Grice, 1975):

The I-Principle (Levinson, 2000, p. 114)

'Say as little as necessary; that is, produce the minimal linguistic information sufficient to achieve your communicational ends (bearing Q in mind)'.

The Q-principle is hearer oriented (Horn, 1989). In other words, under the Q-principle, the listener assumes that the speaker provides enough information for the listener to infer that what the speaker has left unsaid is not true. This derived meaning to which the Q-principle applies is called Q-implicature (also 'generalized conversational implicature') Scalar implicature have been categorized as a kind of Q-implicature (Gazdar, 1979; Hirschberg, 1991; Horn, 1989; Levinson, 1983; Levinson, 2000).

Along this line, good is analysed as a position on a scale consisting of a contrasting set of alternates <excellent, good> (Horn, 1989, p. 232; Levinson, 2000, p. 220): It is assumed that the semantically stronger expression, excellent, and a weaker expression, good, form a scale, and that the speaker's choice of good places his or her meaning at a certain point on this scale and not further. It is assumed that in an expanded positive scale such as <excellent, good, ok>, and a negative scale such as <terrible, bad, mediocre>, each item in the positive range implies the negation of the meaning of the stronger item in the positive range (that is, the more positive item) and vice versa. According to the Q-principle, the speaker provides sufficient information; thus, the speaker's choice of an informationally weaker expression, good, as opposed to an informationally stronger expression, excellent, conveys that the quality is generally not over good level. For example, if someone says It was good, then the listener interprets this to mean that it was good but not excellent, because the speaker used the weaker form. Therefore, from such an utterance, the implicature <It was not excellent> is derived. As a result of this particular Q-inference, good is regarded as having a default scalar conversational Qimplicature, <not excellent> (Levinson, 2000, p. 221).

\section{THE USE OF GOOD ACROSS CONTEXTS}

Levinson's Q-inference-based account, however, has only a limited ability to deal with the communicated meanings of a wide range of uses of good. This section examines whether and how the scalar implicature of good is generated in different contexts by adopting Katsos, Breheny, and Williams' context schema of upper-bound, lower-bound, and neutral discourse contexts (Katsos et al., 2005).

\section{A. Upward-entailing Structures with an Upper-bound Discourse Context}

Katsos, Breheny, and Williams (2005) analyse the generation of a scalar implicature according to context type. ${ }^{1}$ They distinguish contexts based on the semantic entailment of the sentence and the purpose of discourse. Upward-entailment is the semantic inference that allows valid entailment to a superset from a subset (Saeed, 2009). Affirmative sentences are an example of upward-entailing structures-for instance, in the case below, if (3a) is true, logically (3b) is necessarily also true, but if (3b) is true it does not necessarily mean that (3a) is true; thus, (3a) entails (3b), but not vice versa. $^{2}$

(3) a. Mary bought an Italian ice cream.

b. Mary bought an ice cream.

An upper-bound discourse context is one in whose purpose scalar implicature plays an important role-in other words, where it has relevance in conversation. Relevance is a psychological property, and an utterance is regarded as having relevance as an input only when it achieves a cognitive effect (Sperber \& Wilson, 1995; Sperber \& Wilson, 2006). ${ }^{3}$

\footnotetext{
${ }^{1}$ Katsos et al. (2005) demonstrate experimentally that a scalar implicature of some, for example, may or may not be generated depending on the context. For further discussion about the generation of scalar implicature across the three types of context, see (Breheny, Katsos, \& Williams, 2006).

${ }^{2}$ In contrast, negative sentences are an example of downward-entailing structures, meaning those whose semantic inference entails a subset from a superset. For instance, below, if (1b) is true, (1a) is logically true, but not vice versa. Thus, (1b) entails (1a), but not vice versa.

(1) a. Mary did not buy an Italian ice cream.

b. Mary did not buy an ice cream.

The antecedents of conditionals, and relative clauses modified by a universal quantifier every, are also characterised as downward-entailing structures. ${ }^{3}$ According to Sperber and Wilson (1995), the cognitive effect of an utterance is achieved by interacting with and strengthening or eliminating the listener's existing assumptions or by producing new ones.
} 
Let us take the following example of an upward-entailing structure with an upper-bound discourse context. In the following situation, where a film is being selected for an Academy Award nomination or an everyday situation; for example, Bill is looking for an excellent one,

(4) Bill: How was the movie?

Sue: It was good.

good triggers the scalar implicature <not excellent>. The purpose of Bill's utterance is to check the quality of the movie and make possible the identification of an excellent movie. Bill believes that Sue will choose the most informative expression and convey the upper-bound meaning. The implicature is very important in this context, where it is expected that sufficient information, as far as Sue can give it, will be provided. Bill interprets Sue's utterance as implying that $<$ It was good, but it wasn't excellent $>$, because Sue chose the weaker alternative good instead of excellent. If Sue had thought the movie was excellent, she would have used the word excellent.

\section{B. Upward-entailing Structures with a Lower-bound Discourse Context}

A lower-bound discourse context is one where inference of scalar expression is not needed, and the basic (or 'plain', in Katsos et al.'s term (2005) meaning satisfies the purposes of the discourse. In other words, a lower-bound discourse context is a situation where a scalar implicature does not have discursive relevance. In some conversational contexts, scalar implicature is not induced-for example, when good does not trigger any special meaning:

(5) Bill: Why are you going to COEX? ${ }^{4}$

Sue: I want to see a good movie.

In (5), good should be taken in its barest, most basic meaning. Bill is showing interest in Sue's plans. He is not expecting any judgment of quality from Sue about any movies. Thus, Bill does not proceed to the inference of any deeper or more complex meaning of good. Sue's response itself satisfies the purpose of Bill's utterance and does not activate a scalar implicature.

\section{Upward-entailing Structures Which Are Discourse Neutral}

A neutral context is one where the listener is not sure whether it is upper- or lower-bound, and thus appears in situations where there is no clue or assumption that helps the listener judge if a scalar implicature would have relevance or not. Consider:

(6) The director saw some good movies. He is going to check the others later.

(7) It is a good movie, too.

In (6) and (7), we are not sure whether good means < good, not excellent> or just < good> or <simply good>. This is because we do not know the purpose of the discourse in these utterances and thus cannot be certain about the generation of scalar implicatures. It is very common to hear good in this kind of context. Examples include when we happen to overhear part of someone's speech, read a newspaper headline or advertisement slogan, and so on. In these cases, we cannot identify whether good is used in an upper-bounding or a lower-bounding context: There might be a scalar implicature or there might not.

\section{DifFerences in the Meaning of Good in Upward-entailing Structures Which Are Discourse Neutral}

As we have seen in section III.A. above, it is clear that good has a scalar implicature when it appears in an upwardentailing structure with an upper-bound context. This case has been analysed by Horn (1989) and Levinson (2000). However, we also need to focus on the interpretation of good in contexts where the purpose of the utterance is not clear from the listener's perspective. This section discusses the communicated meanings of good in a neutral context by considering speaker-oriented rather than hearer-oriented interpretations (that is, those which focus on the characteristics of the speaker's specific utterance, rather than assuming an ideal speaker and focusing on the hearer's understanding), and investigates how these meanings are recovered.

\section{A. Non-Q-implicature}

People often use good when expressing a positive feeling. For example,

(8) Bill: Do you like it?

Sue: Needless to say, it's good.

Here, Sue expresses that she is fully satisfied with 'it' and does not need to provide more information on this point. Her utterance signals an ample degree of satisfaction. Sue does not want to go into great detail about it, and her utterance is sufficiently (not weakly) informative given Bill's question. Furthermore, strictly speaking, she does not convey her awareness of the weak informativeness of her utterance to Bill. That is, Sue does not care how her use of the scalar expression good is interpreted. Here, unless Bill is evaluating the quality of 'it', Q-inference is not required.

\section{B. I-implicature}

Consider the following utterances:

\footnotetext{
${ }^{4}$ A mall in Seoul.
} 
(9) a. I am glad I got a good score in the PGA competition.

b. You have to memorize these to get a good score.

The communicated meaning of good in each utterance is not accounted for by applying the Q-principle. That is, (9a) could be said by (e.g.) a golfer who has won a competition, for instance during a TV interview. In this case the communicated meaning of good could be recovered as something close to <excellent>. In contrast, (9b) could be said by a language class instructor urging the students to listen and remember some vocabulary items. In this situation, the listeners will not interpret the meaning of good as <not excellent> as generated by the Q-principle; instead, they are likely to interpret it as <very high or the highest score>.

The communicated meanings of good in (9) constitute strengthened or supplied content based on context. The recovered (specified) meanings of each utterance can be analysed by applying Levinson's I[nformativeness]-principle (Levinson 2000). According to the I-principle, the speaker needs not state the obvious. Even if the speaker says little, the listener can infer a stereotypical meaning from social (non-linguistic) and world knowledge. This principle is speaker-oriented. Meaning under the influence of the I-principle is called 'I-implicature'.

On the basis of the I-principle, the listener does not expect the speaker to say too much or speak in detail. In (9a) the listener can derive meanings such as <in the top range>, <one of the top three>, or <first, second, or third prize>. This is because the listener infers a meaning from related background knowledge. If, for instance, an athlete who has performed well in a competition describes his or her feat and the situation surrounding it in detail in an interview, the listener may question why the athlete needs to give so much detail. This question may presume that it is natural for the speaker to desire to appear modest and thus to minimize 'praise of self' (Leech, 1983, p. 136), so that listeners do not think that he or she is bragging. Similarly, in (9b), the listener likely does not want the speaker to say something like, for example, 'You have to memorize these to get a good score ... that is, if your goal is IELTS 6.5, a score of 6.5, or if your goal is IELTS 7.0 or above, a score of 7.0 or above'. It would be quite superfluous to provide this information because it can be inferred without difficulty by various listeners according to their needs.

\section{A Gap between the Speaker's Meaning and the Default Scalar Implicature}

Speakers with different expectations can convey different meanings by saying good. In the following conversation, the communicated meaning of good varies according to Jane's expected score.

(10) Bill: What did you get?

Jane: I got a good score.

Let us imagine some different situations.

(i) If Jane had expected and got a B, good would just mean good-<as expected $>$ or <not bad $>$. When expectations are not high, good seems to mean <not bad>.

(ii) If Jane had expected a C or a D but actually got a B, she could mean that her score was <satisfactory>, <better than expected>, or <not bad $>5$

(iii) If Jane had expected a B+ and got a B, good could mean <a little less than expected>.

(iv) There may be no particular expectation, in which case the speaker may just mention the grade, B, with no room for implicature. In this case, good will not be used, though it might be mentioned, as for example It says 'good' on my report card.

It must be highlighted that in these situations, no Q-implicature (scalar implicature) of good in Jane's utterance is intended at all and can be excluded by the listener if he or she already knows Jane's expectation of her score. ${ }^{6}$

The implicature <not bad> of good is not accounted for by Q-inference, because there is no entailment relation between the linguistic forms good and bad (the degree of semantic informativeness between them is not established); thus, a scale like $*$ good, bad> (or vice versa) is impossible. Horn (1989, p. 232) suggests a positive scale such as <excellent, good, ok>, and a negative scale such as <\{terrible/awful $\}$, bad, mediocre>, not something like $*<$ good, bad $>$ - an argument which was accepted by Levinson (2000, p. 128). In Horn's unidirectional scale, scalar implicature is generated within a positive scale or within a negative scale, separately:
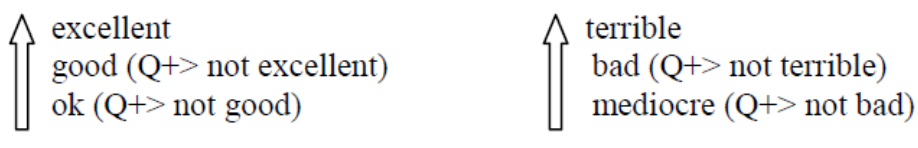

( $+>$ implicates $)$

Differences between I-inferences and Q-inferences (Levinson, 2000, p. 119) are illustrated below:

\footnotetext{
${ }^{5}$ If Jane had heard a lot of concern expressed by her teachers about her previous academic performance, her utterance in (10) might have implied that her score was an improvement on her previous results; that is, she could have meant <I got a very good score $>$ or $<\mathrm{I}$ got an excellent score $>$ (by her own criteria), or $<\mathrm{I}$ wasn't required to see my teacher after the test $>$. The latter meaning is regarded as a 'particularized conversational implicature', because the listener needs a special scenario in order to derive it.

${ }^{6}$ It may be possible for the listener who focuses on Jane's use of this lexical item to interpret good as <not excellent> due to her use of a semantically weak form.
} 


\begin{tabular}{|l|l|}
\hline I-inferences & Q-inferences \\
\hline $\begin{array}{l}\text { inferences to more (situation-)specific } \\
\text { interpretations }\end{array}$ & $\begin{array}{l}\text { inferences to more (scalarly) precise } \\
\text { interpretations }\end{array}$ \\
\hline positive in character & negative in character \\
\hline typically guided by stereotypical assumptions & no reference to stereotypical assumptions \\
\hline non-metalinguistic & metalinguistic \\
\hline
\end{tabular}

(We have inserted 'situation-' and 'scalarly' into this table from Levinson (2000) to clearly show the differences between I-and Q-inference.)

The case where good implies <not bad> is not mentioned among Levinson's pragmatic inferences (Levinson, 2000). ${ }^{7}$ The surface form of the conveyed meaning <not bad> is negative, and this aspect can lead us to link this case to the negative character of the Q-inference; thus, <not bad> could fall into the category of Q-implicature. However, in terms of the speaker's intention in using good instead of not bad, it is possible to assume that the speaker focuses on some positive aspect of the thing being referred to-although she could also have a negative opinion at some deeper level. The speaker's use of good, instead of not bad, can thus be considered a politeness strategy, because of the facethreatening nature of the evaluation. The speaker is conscious of the imperative to save face and wants to keep 'positive face' (that is, to be perceived as confident). For instance, we tend to hide our real emotions and say something like 'I'm good' even when we are actually not happy with ourselves or the situation. In some cases, good may be used to avoid potential threats to the listener's face (cf. Brown \& Levinson, 1987). It may reveal the speaker's unwillingness to express a negative evaluation and/or a desire to comfort the listener. This aspect of language use can be influenced by rapport management concerns (Spencer-Oatey, 2008), in that the speaker may want to mitigate a rapport-threatening situation. It seems that this kind of metapragmatic inference may intrude in the derivation of the implicature <not bad> from good. In Levinson's framework, however, the positive property of inference belongs to the category of I-inference, not Q-inference. Thus, one cannot help but place the communicated meaning <not bad> under I-inference. Another possible communicated meaning of good, such as <better than expected $>$, falls into the realm of I-inference because it is a more situation-specific interpretation. The discussion above is visualized in Table 1.

TABLE 1.

EXPECTATION LEVEL AND SPEAKER MEANINGS OF GOOD

\begin{tabular}{|l|l|l|l|l|}
\hline $\begin{array}{l}\text { Speaker's expectation } \\
\text { (or lack of expectation) }\end{array}$ & Expectation level & Actual score & Possible intended meanings & Inference type \\
\hline expectation & B & B & basic (literal) meaning & NA \\
\hline expectation & C or D & & not bad & $\begin{array}{l}\text { better than } \\
\text { expected }\end{array}$ \\
\hline & & B & satisfactory & I \\
\hline expectation & $\mathrm{B}+$ & $\mathrm{B}$ & vot bad & very good or excellent \\
\hline no expectation & & $\mathrm{B}$ & a little less than expected \\
\hline
\end{tabular}

\section{Combinations of I- and Q-inference}

We have tried to show that the conversational implicatures of good reflect the speaker's meaning in concrete situations. This section concerns the intrusion of the I-principle into the interpretation of good. If the speaker does not feel the need to clarify her meaning sufficiently (that is, if she does not need to observe the Q-principle), in conflict with the listener's want, her meaning is likely to be inferred by the listener with resort to the resources available. Consider the following utterance:

(11) Lee Chung-Yong is a good soccer player.

Speakers may not always be conscientious in terms of using linguistically precise and informative forms in a situation where clarification is not needed to achieve their communicative intent, leaving, for example, different ways of interpreting good available depending on listeners' personal histories, cultural backgrounds, prior interaction with the speaker, etc. For instance, in (11), the Korean listener is likely to automatically recover the conversational implicature of good as <best>, <excellent> (I-implicature). In contrast, the British listener is more likely to interpret good as <not excellent> (Q-implicature). This Q-implicature comes from a scale consisting of <\{excellent/best $\}$, good $>$; the implicature <not excellent> evidences a high standard for footballing ability on the part of the listener. Lee ChungYong, a member of the English Premier League football team Bolton Wanderers, is regarded as a competent player. His reputation is high enough that he is called by the nickname 'Blue Dragon'. However, there will be a perceived gap in

\footnotetext{
${ }^{7}$ Horn (1989) and Levinson (2000) mention the case where not bad implicates <good>, and account for it by reference to R-inference (Horn) and Iinference (Levinson), respectively. The R-principle emerges from Grice's Relation, Second Quantity, and Third and Fourth Manner maxims. According to the R-principle, the speaker is expected to give only necessary information, because the listener can infer the intended meaning ba sed on social or cultural knowledge. A meaning inferred via the R-principle is called an R-implicature (Horn, 1984, Horn, 1989, p. 194).
} 
ability between Lee and global stars like Lionel Messi or Wayne Rooney as perceived by British football fans, who are used to a high standard of play. In the case of Korean fans, in contrast, simply being a member of any EPL team will be seen as 'good' or 'excellent'. Even if a different I-implicature, such as <impressive>, is derived from good, the utterance in (11) might be recovered as, for instance, <Lee Chung-Yong is an impressive player with the potential to become better>.

In Levinson's theory, Q-inference and I-inference are proposed to be separate mechanisms in utterance interpretation, with Q-inference motivating the interpretation of scalar expressions. While Q-inference is based on linguistic factors (semantic strength of linguistic expression), I-inference is guided by ideas in common. These two types of inferences in some cases seem to complement each other in the interpretation of good based on contextual assumptions; that is, when arriving at the speaker's meaning, the listener cannot ignore contextually plausible or stereotypical interpretations. The meaning of good can be enriched from the surrounding situation. For instance, precisely speaking the implicatures about Lee Chang-Yong above are partly I-inferred and partly Q-inferred, since the first part of the range of the implicature is derived from non-linguistic knowledge (Lee's performance) and the latter part from linguistic elements (the use of the informationally weak expression good). With less evaluation or precision pressure between speaker and listener, good may generate such an I-implicature. That is, the conversational implicature of good can be determined by the interaction of Q-inference (expectation of preciseness) with I-inference (allowance for approximation in language use) in context.

\section{E. Projection Problem}

An utterance has a range of pragmatic meanings. Consider:

(12) Good movies are usually popular with most people, and excellent movies can be either popular with or overlooked by ordinary people, depending on their content.

whose potential implicatures can be represented as follows:

a. Q-scalar implicature of good

It is not the case that excellent movies are usually popular with most people>

b. Q-clausal implicature of the disjunction ${ }^{8}$

$\mathbf{P}$ (Excellent movies can be popular with ordinary people, depending on their content)

c. Q-clausal implicature of the disjunction

P (Excellent movies can be popular with ordinary people, depending on their content)

d. Q-clausal implicature of the disjunction

$\mathbf{P}$ (Excellent movies can be overlooked by ordinary people, depending on their content)

e. Q-clausal implicature of the disjunction

$\mathbf{P} \sim$ (Excellent movies can be overlooked by ordinary people, depending on their content)

f. I-implicature of the whole utterance

$<$ Excellent movies are generally popular with critics, as can be expected, because they are good, but excellent movies are not necessarily popular with ordinary people, because excellent movies focus on artistry, not popularity>

g. I-implicature of the whole utterance

<In contrast to general assumptions, some excellent movies gain popularity and some don't>

Here, (a) is the implicature of good on a scale <excellent, good>, while (b)-(e) are the clausal implicatures of the disjunction (or) in the second sentence. Implicatures (a) and (b) clash, so (a) is cancelled, and the whole sentence can receive the implicatures from (b) to (e). ${ }^{9}$ In contrast, (12) invites I-inference (specified inference) about the relation between the quality of movies and their popularity. When we say good movies, we are generally thinking of movies that are liked by people and thus popular. Then, when we think of excellent movies, we are likely to think they should be more popular because they are very good movies, very well made. However, some excellent movies may be hard to understand from the perspective of ordinary people as opposed to that of, say, a film critic, and may thus be underappreciated by ordinary people although their formal quality is excellent. From the sentence as a whole, we may recognise that the speaker in mind has a distinct subset within the set of good movies, and we are likely to recover an implicature for good movies such as <movies focused on popularity rather than quality>, which is specified by I-

\footnotetext{
${ }^{8}$ Gazdar (1979) proposes that the assertion of some complex structures generates certain clausal implicatures. For example, the choice of the disjunction $p$ or $q$ conveys that the speaker is unsure which side of the disjunction is true. If the speaker knew, he or she would have made a stronger statement by using the conjunction, $p$ and $q$. Thus, utterances of the form $p$ or $q$ have the following implicatures: $\{\mathbf{P} p, \mathbf{P} \sim p, \mathbf{P q}, \mathbf{P} \sim q\} ;$ in other words, it is possible that $\mathrm{p}$, also that not $\mathrm{p}$, also that $\mathrm{q}$, also that not $\mathrm{q}$. (P indicates POSSIBILITY in logic.)

${ }^{9}$ In Grice's (1975) model, both generalized and particularized conversational implicatures are cancellable. Some meanings can survive in combinations of words or components into larger structures; this is referred to as the projection problem. Levinson (2000, p. 162) proposes the projection principle to address this problem by explicating how inconsistent generalized conversational implicatures that arise are resolved by ordered priority, as follows: 'Aspects of utterance content should be added to the content $\mathrm{C}$ of utterance $\mathrm{U}$ in the following order:

1). the entailments of $U$

2). the potential clausal Q-implicatures of $U$

3). the potential scalar Q-implicatures of $U$

4). the potential M-implicatures of $U$

5). the potential I-implicatures of U.'
} 
inference. Thus, some listeners may infer (f).The I-implicatures in (12) are more clearly perceived than the Q-clausal implicature. It should be noted that (f) and (g) are not inconsistent and do not clash with each other; however, implicature ( $\mathrm{g}$ ) seems to be the preferred interpretation over implicature (f). On the other hand, from the sentence as a whole, a Q-scalar inference of good does not arise, and an upper-bounded meaning of good, such as <good but not excellent>, is not generated. Levinson $(1987,1995,2000)$ treats generalized conversational implicatures as the result of the local (subsentential) inferences through lexical items from a contrast set (Reboul, 2004). This is based on Gricean reasoning, specifically the view of generalized conversational implicatures as 'the use of certain form of words in an utterance would normally carry such-and-such an implicature or type of implicature' (Grice, 1975, p. 56). Sperber and Wilson (1995), Carston (2002), and Bach (2006) have pointed out that sentences might not have generalized conversational implicatures. For experimental studies of this related issue see (Bezuidenhout \& Morris, 2004; Rebould, 2004). Their findings seem to support the underspecification model derived from relevance theory views (Carston, 2000; Sperber \& Wilson, 1995). However, here global- (sentential-) level inferences are involved in some cases. In the case of (12), an I-implicature for the whole utterance is activated.

\section{CONCLUSION}

This paper has focused on the communicated meaning of the English scalar expression good in various contexts and examined its inferential aspects using Levinson's (2000) framework. This paper has shown that different types of inferences can be involved in the interpretation of good, and that it does not have to be exclusively upper-boundedly interpreted. In particular, this paper has pointed out that good in a neutral context can convey different meanings according to the speaker's level of (scalar) expectation. Its meaning can also be recovered as an I-implicature (and/or Qimplicature) by a listener who is aware of the speaker's expectation or who has an expectation of his or her own. It thus appears that deciding whether to derive a scalar implicature for good is a cognitive process involving both expectations and processing of input from context (e.g. the recognition of an upper-bound discourse context). Inference of a specific meaning from a speaker who simply says good is within the realm of I-inference, which appears to be involved in deriving the speaker's meaning. This observation suggests that it could be inadequate to fix the default meaning of good as <not excellent>, as would be indicated by the Q-Principle, and that in general the Q-principle may not always be sufficiently able to deal with the complexities of the pragmatic meaning of good.

\section{REFERENCES}

[1] Bach, K. (2006). The top 10 misconceptions about implicature. In B. Birner \& G. Ward (eds.), Drawing the boundaries of meaning: Neo-Gricean studies in pragmatics and semantics in honor of Laurence R. Horn. Amsterdam: John Benjamins, 2130.

[2] Bezuidenhout, A. L. \& R. K. Morris. (2004). Implicature, relevance and default inferences. In I. Noveck \& D. Sperber (eds.), Experimental pragmatics. London: Palgrave Macmillan, 257-282.

[3] Breheny, R, N. Katsos \& J. Williams. (2006). Are generalized scalar implicatures generated by default? An on-line investigation into the role of context in generating pragmatic inferences. Cognition 100, 434-463.

[4] Brown, P. \& S. C. Levinson. (1987). Politeness: Some universals in language usage. Cambridge: Cambridge University Press.

[5] Carston, R. (2002). Thoughts and utterances: The pragmatics of explicit communication. Oxford: Blackwell.

[6] Gazdar, G. (1979). Pragmatics: Implicature, presupposition, and logical form. New York: Academic Press.

[7] Grice, H. P. (1975). Logic and conversation. In P. Cole, and J. Morgan (eds.), Syntax and semantics 3: Speech acts. New York: Academic Press, 41-58.

[8] Hirschberg, J. (1991). A theory of scalar implicature. New York: Garland Publishing.

[9] Horn, L. R. (1984). Toward a new taxonomy for pragmatic inference: Q-based and R-based implicature. In D. Schiffrin (ed.), Meaning, form, and use in context. Washington DC: Georgetown University Press, 11-42.

[10] Horn, L. R. (1989). A natural history of negation. Chicago: University of Chicago Press.

[11] Katsos, N., R. Breheny \& J. Williams. (2005). Interaction of structural and contextual constraints during the on-line generation of scalar inferences. In G. Bruno, L. Bara \& M. Bucciarelli (eds.), Proceedings of the 27th Annual Conference of the Cognitive Science Society. Mahwah, NJ: Lawrence Erlbaum Associates, 1103-1118.

[12] Leech, G. N. (1983). Principles of pragmatics. London: Longman.

[13] Levinson, S. C. (1983). Pragmatics. Cambridge: Cambridge University Press.

[14] Levinson, S. C. (1987). Implicature explicated? Behavioral and Brain Sciences 10, 722-723.

[15] Levinson, S. C. (1995). Three levels of meaning. In F. Palmer (ed.), Grammar and meaning. Cambridge: Cambridge University Press, 90-115.

[16] Levinson, S. C. (2000). Presumptive meanings: The theory of generalized conversational implicature. Cambridge, MA: MIT Press.

[17] Reboul, A. (2004). Conversational implicatures: Nonce or generalized? In I. Noveck \& D. Sperber (eds.), Experimental pragmatics. London: Palgrave Macmillan, 322-333.

[18] Saeed, J. (2009). Semantics. Oxford: Wiley-Blackwell.

[19] Spencer-Oatey, H. (2008). Culturally speaking: Managing rapport through talk across cultures. London: Continuum.

[20] Sperber, D. \& D. Wilson. (1995). Relevance: Communication and cognition. Oxford: Blackwell.

[21] Sperber, D. \& D. Wilson. (2006). Relevance theory. In R. Horn \& G. Ward (eds.), The handbook of pragmatics, 607-632. Oxford: Blackwell. 
Jiyon Cook attained her PhD in English linguistics at Sogang University, Seoul, South Korea in 2003. She is a lecturer in the Department of British and American Language and Culture at Sogang University in Seoul. She has previous publications in the Journal of the Discourse and Cognitive Linguistics Society of Korea. Her research interests are in pragmatics, discourse analysis, and semantics. Her current research interests are intercultural pragmatics and interlanguage. Dr. Cook is a member of the International Pragmatics Association, and the Korean Association for the Study of English Language and Linguistics. 